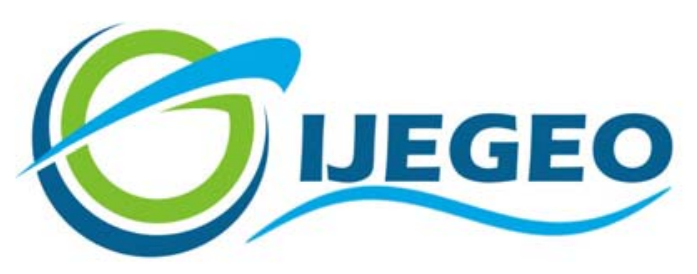

International Journal of Environment and Geoinformatics (IJEGEO) is an international, multidisciplinary, peer reviewed and certified open access journal.

\title{
On Some Climatic Scenarios For Turkey From The Perspective of Changes in the Annual Mean Temperatures via Aggregation by Steady- State Distribution
}

\author{
Salih Çelebioğlu \\ Editors \\ Prof. Dr. Cem Gazioğlu, Prof. Dr. Dursun Zafer Şeker, Prof. Dr. Ayşegül Tanık, \\ Prof. Dr. Şinasi Kaya, Assist. Prof. Dr. Volkan Demir
}

\section{Scientific Committee (2018)}

Dr. Abdullah Aksu, Prof. Dr. Bedri Alpar, Prof. Dr. Gülşen Altuğ, Prof. Dr. Lale Balas, Prof. Dr. Can Balas, Prof. Dr. Levent Bat, Prof. Dr. Bülent Bayram, Prof. Dr. Nuray Çağlar, Prof. Dr. Jadunandan Dash, Prof. Dr. A. Evren Erginal, Dr. Dieter Fritsch, Dr. Amin Gharehbaghi, Assoc. Prof. Dr. Tolga Görüm, Prof. Dr. Melike Gürel, Dr. Hakan Kaya , Prof. Dr. Fatmagül Kılıç, Assoc. Prof. Dr. Maged Marghany, Prof. Dr. Nebiye Musaoğlu, Prof. Dr. Masafumi Nakagawa, Prof. Dr. Haluk Özener, Prof. Dr. Erol Sarı, Prof. Dr. Elif Sertel, Prof. Dr. Nüket Sivri, Assoc. Prof. Dr. Füsun Balık Şanlı, Prof. Dr. Uğur Şanlı, Assoc. Prof. Dr. Hasan Özdemir, Prof. Dr. Taşkın Kavzoğlu, Msc. Mustafa Üstüner, Assoc. Prof. Dr. Oral Yağcı, Prof. Dr. Seyfettin Taş, Assoc. Prof. Dr. Ömer Suat Taşkın, Assoc. Prof. Dr. İ. Noyan Yılmaz, Dr. Baki Yokeş, Dr. Sibel Zeki 


\title{
On Some Climatic Scenarios For Turkey From The Perspective of Changes in the Annual Mean Temperatures via Aggregation by Steady- State Distribution
}

\author{
Salih Çelebioğlu \\ Independent Researcher \\ E-mail : celebicik@yahoo.com

\begin{abstract}
In this study, it is tried to give a system of Markov chains approach to the trend of annual mean temperatures in Turkey. For this reason, a data of annual mean temperatures between the years 1965 - 2012 of 58 meteorological stations of Turkey are used. Each scenario is given as a solution to a quadratic programming problem for which is spanned by the transition matrices of twelve groups. The steady-state distribution method given here facilitates the multiple station Markov chain applications. In the meantime, the linear regression approaches in which the averages of station groups are considered as independent variables are as well introduced. It is also given comments on some scenarios while an extreme scenario as a solution to a few problems is pointed out to which is feared in respect of climatic change.
\end{abstract}

Keywords: Annual mean temperatures, climatic change, Markov chain, Aggregation by steady-state distribution, Linear regression

\section{Introduction and Motivation}

The climate is the slowly varying aspects of the atmosphere-hydrosphere-land surface system, according to the American Meteorological Society. Climate is used for a statistical description, for example, such as the average temperature or precipitation over a period of time which measures the variations on these quantities (Dessler, 2012, p.1). Briefly, the climate is the average weather conditions that do not change for many years in a very large area.

Climate change is any systematic change in the long-term statistics of climate elements such as temperature, precipitation, pressure or wind speeds over several decades or longer, again by the American Meteorological Society (Dessler, 2012, p.4).

An important part of climate change studies is about temperature changes. According to our search on Scholar.Google (April 24, 2017), about one seventh of all climate change studies involve precipitation changes. The same research points out in about $4 \%$ of climate change studies the temperature changes and precipitation changes take place together.

There are a number of studies made on the annual mean temperature changes in Turkey. Dogan et al. (2015) on the trend directions by backward- and forward-shifted methods, Kadioglu (1997) on the trend analysis by the Mann-Kendall test, Ustaoglu (2012) on the trend analysis by the Mann-Kendall test for the North-west of Turkey, Can and Atimtay (2002) on the trend and abrupt changes by the Mann-Kendall and Wald-Wolfowitz tests, Karaburun et al. (2012) on the trend of annual mean temperatures for Marmara region by the Mann-Kendall test and Theissen polygons, Tayanc et al. (1998) on the inhomogeneity of annual mean temperatures in Turkey by the Wald-Wolfowitz and Kruskal-Wallis tests, among others. As it is known, the MannKendall and Wald-Wolfowitz tests are nonparametric tests. Among these techniques, there are some other methods, known as Theissen polygons, the inverse distance 
weights and kriging. The first two methods are based on the catchment geometry (Ball and Luk, 1998), and the third method is known as a method of interpolation for spatial data. These methods are generally used for the rainfall and temperature data. For the details and history of kriging see Stein (1999).

In this study, we used the steady-state distribution of Markov chains to aggregate the stations. Since kriging has a stochastic spatially dependent component, in a sense, our approach resembles kriging. In essence, the purpose of this study is to give some explanations of considered models and catch a direction to climate change by comparing the station groups in terms of their frequencies included in the models.

In average temperature changes, the increases and decreases are primarily striking. As the explained reasons in the next section, let us denote the increases in mean temperatures in successive years by 1 and the decreases or unchanges by 0 . The transition matrix estimated from the mean of annual mean temperature changes of 58 meteorological stations for 48 years, which is the subject of our research, by the Maximum Likelihood method is

$$
P=\left[\begin{array}{ll}
0.28571 & 0.71429 \\
0.60000 & 0.40000
\end{array}\right],
$$

and its steady-state distribution is

$$
\pi=\left[\begin{array}{ll}
0.4565 & 0.5435
\end{array}\right] .
$$

Looking only at these results, it can be worried about climate change, because according to the steady-state distribution, it is expected that in the long run $45.65 \%$ of all times the average temperatures will decrease or not change, and increase $54.35 \%$. In other words, in the average temperatures it would be expected a decrease in every 1.84 years, even though it is expected to decrease or remain unchanged at about every 2.19 years, in the long term. And this transition matrix will again be considered in Section 4. By these comments, we can be pessimistic. In a sense, we will discuss some details that can be called as scenarios in the following sections.

\section{Methodology and Models}

Since the climate system is one of the most complex systems that scientists have tried to come to grips with, there are many approaches to understanding this system and new approaches are still ongoing. One of these approaches is to take advantage of the simulated system by generating as much system dynamics as possible in powerful computers. But the most powerful supercomputers have not also been able to capture all the processes of system dynamics. So, instead of complex numerical models, scientists are directed to simple conceptual models. Stochastic models are such a conceptual tool to understand better the climate system (Imkeller and von Storch, p.vi). Since for the climate system there are, in general, lots of data obtained from many stations, Markov chain and point process models are similar to the extent that they are restricted to single-station applications, and are not easily generalizable to multiple station applications. References to the Markov chains and related derived models can be seen in (von Storch and Navarra, 1995, p.201). In the case of an irreducible or ergodic Markov chain, it is appropriate to consider the steady-state distribution from the asymptotic analysis point of view (Clark, 2008, p.46). Taking this in mind, it is tried to give a new model to deal with multiple stations through steady-state distribution.

Aggregation and decomposition to reduce the state space are two general techniques to solve large scale Markov decision processes (Boucherie and van Dijk, 2017, p.372). Aggregation has different kinds of purposes, such as state aggregation and time aggregation. In other words, the key idea in aggregation is to lead to an effective reduction of dimensionality (Yin and Zhang, 2013, p.53). However, in contrast to state aggregation, which generally results in an approximate model due to the loss of Markov property, time aggregation suffers no loss of accuracy, because the Markov property is preserved. (Cao, et al., 2002). For the theory, 
applications and details of aggregation in Markov models see (Anisimov, 2008, Chapters 8-10), and the references therein.

For this study, the data of annual mean temperatures between the years 1965 - 2012 of 58 meteorological stations of Turkey are used. As there are few data such as 48 years, it is observed both the autocorrelation coefficients of the each station and of each of the station groups up to the 12th lag are smaller than the $\operatorname{AR}(1)\left(\beta_{1}\right)$ coefficient in respect of their absolute values. For this reason, and the emphasis that temperature changes can be modeled by Markov chains in many cases in Dobrovolski (2000), we decided to use a homogeneous Markov chain model consisting of a state space 0 and 1 . In this Markov chain, the cases are taken as the state 0 if the difference of mean temperatures between consecutive years is negative or zero, and as the state 1 , if the difference is positive. Thus, it can be said that the state 0 represents the case the mean temperatures do not change or decrease and the state 1 represents the case the mean temperatures increase. Under this state determination, the transition matrices for each of the 58 stations are estimated by the Least Squares method and then their steady-state distributions are found. By the observation on the steady-state distributions it was determined that 58 stations have 12 different steady-state distributions up to 4 th decimal place.

Table 1. Meteorological stations distribution by climatic zones (geographical regions).

\begin{tabular}{|l|l|l|}
\hline $\begin{array}{l}\text { Climatic Zone } \\
\text { (Geographical } \\
\text { Region) }\end{array}$ & Stations Name & Station ID \\
\hline Black Sea & Amasya, Artvin, Bartin, Bayburt, & $17085,17045,17020,17089$, \\
& $\begin{array}{l}\text { Bolu, Duzce, Giresun, Gumushane, } \\
\text { Kastamonu, Ordu, Rize Samsun, }\end{array}$ & $\begin{array}{l}17070,17072,17034,17088, \\
17074,17033,17040,17030, \\
\text { Sinop, Tokat }\end{array}$ \\
\hline Marmara & Bilecik, Bursa Edirne, Kirklareli, & 17026,17086 \\
& Kocaeli, Yalova & $17066,17116,17050,17052$, \\
\hline Central Anatolia & Aksaray, Ankara, Cankiri, Karaman, & $17192,17130,17080,17246$, \\
& Kayseri, Kirsehir, Nevsehir, Sivas, & $17196,17160,17193,17090$, \\
& Yozgat & 17140 \\
\hline Aegean & Afyonkarahisar, Aydin, Denizli, & $17190,17234,17237,17220$, \\
& Izmir, Kutahya, Mugla, Usak & $17155,17292,17188$ \\
\hline Mediterranean & Adana, Antakya, Burdur, Isparta, & $17351,17372,17238,17240$, \\
& Kahramanmaras, Mersin & 17255,17340 \\
\hline Eastern Anatolia & Ardahan, Bingol, Elazig, Erzincan, & $17046,17203,17201,17094$, \\
& Igdir, Malatya, Mus, Tunceli, Van & $17100,17199,17204,17165$, \\
& & 17172 \\
\hline $\begin{array}{l}\text { South East } \\
\text { Anatolia }\end{array}$ & Adiyaman, Gaziantep, Kilis, & $17265,17261,17262,17275$, \\
& Mardin, Sanliurfa, Siirt & 17270,17210 \\
\hline
\end{tabular}


Table 2. Station groups by their stations and steady-state distributions.

\begin{tabular}{|c|l|c|}
\hline $\begin{array}{c}\text { Station } \\
\text { Group } \\
\text { No }\end{array}$ & Included Station(s) Name & $\begin{array}{l}\text { Steady-state } \\
\text { Distribution }\end{array}$ \\
\hline 1 & $\begin{array}{l}\text { Adiyaman, Afyonkarahisar, Bartin, Bayburt, Bolu, } \\
\text { Gaziantep, Igdir, Isparta, Kirklareli, Malatya, Mus, Ordu, } \\
\text { Sivas }\end{array}$ & {$\left[\begin{array}{ll}0.5652 & 0.4348\end{array}\right]$} \\
\hline 2 & $\begin{array}{l}\text { Aksaray, Antakya, Ardahan, Bilecik, Bingol, Erzincan, } \\
\text { Kayseri, Kilis, Rize, Siirt, Usak, Yozgat }\end{array}$ & {$\left[\begin{array}{ll}0.5870 & 0.4130\end{array}\right]$} \\
\hline 3 & $\begin{array}{l}\text { Adana, Amasya, Burdur, Cankiri, Düzce, Elazig, } \\
\text { Gumushane, Karaman, Kutahya, Mardin, Yalova }\end{array}$ & {$\left[\begin{array}{ll}0.5435 & 0.4565\end{array}\right]$} \\
\hline 4 & $\begin{array}{l}\text { Ankara, Artvin, Bursa, Edirne, Kastamonu, Mugla, Samsun, } \\
\text { Sinop }\end{array}$ & {$\left[\begin{array}{ll}0.5217 & 0.4783\end{array}\right]$} \\
\hline 5 & Aydin, Denizli, Giresun, Kocaeli & {$\left[\begin{array}{ll}0.5000 & 0.5000\end{array}\right]$} \\
\hline 6 & Nigde, Sanliurfa, Van & {$\left[\begin{array}{ll}0.6304 & 0.3696\end{array}\right]$} \\
\hline 7 & Kirsehir, Nevsehir & {$\left[\begin{array}{ll}0.6087 & 0.3913\end{array}\right]$} \\
\hline 8 & Tokat & {$\left[\begin{array}{ll}0.5869 & 0.4131\end{array}\right]$} \\
\hline 9 & Tunceli & {$\left[\begin{array}{ll}0.5594 & 0.4406\end{array}\right]$} \\
\hline 10 & Kahramanmaras & {$\left[\begin{array}{ll}0.5250 & 0.4750\end{array}\right]$} \\
\hline 11 & Mersin & {$\left[\begin{array}{ll}0.6153 & 0.3847\end{array}\right]$} \\
\hline 12 & Izmir & {$\left[\begin{array}{ll}0.4783 & 0.5217\end{array}\right]$} \\
\hline
\end{tabular}

The estimated transition matrices of 12 station groups are as follows:

$$
\begin{aligned}
& P_{1}=\left[\begin{array}{ll}
0.41420 & 0.58580 \\
0.76154 & 0.23846
\end{array}\right], \\
& P_{7}=\left[\begin{array}{ll}
0.48214 & 0.51786 \\
0.80556 & 0.19444
\end{array}\right], \\
& P_{2}=\left[\begin{array}{ll}
0.42593 & 0.57407 \\
0.81579 & 0.18421
\end{array}\right] \text {, } \\
& P_{8}=\left[\begin{array}{ll}
0.29630 & 0.70370 \\
0.94737 & 0.05263
\end{array}\right], \\
& P_{3}=\left[\begin{array}{ll}
0.37455 & 0.62545 \\
0.74459 & 0.25541
\end{array}\right] \text {, } \\
& P_{9}=\left[\begin{array}{ll}
0.40000 & 0.60000 \\
0.76190 & 0.23810
\end{array}\right] \text {, } \\
& P_{4}=\left[\begin{array}{ll}
0.328125 & 0.671875 \\
0.732950 & 0.267050
\end{array}\right] \text {, } \\
& P_{10}=\left[\begin{array}{ll}
0.44000 & 0.56000 \\
0.61905 & 0.38095
\end{array}\right] \text {, } \\
& P_{5}=\left[\begin{array}{ll}
0.33696 & 0.66304 \\
0.66304 & 0.33696
\end{array}\right] \text {, } \\
& P_{11}=\left[\begin{array}{ll}
0.44828 & 0.55172 \\
0.88235 & 0.11765
\end{array}\right] \text {, } \\
& P_{6}=\left[\begin{array}{ll}
0.49425 & 0.50575 \\
0.86275 & 0.13725
\end{array}\right] \text {, } \\
& P_{12}=\left[\begin{array}{ll}
0.27273 & 0.72727 \\
0.61905 & 0.38095
\end{array}\right] \text {. }
\end{aligned}
$$


Table 3. Autocorrelations for station groups up to lag 12 .

\begin{tabular}{|c|c|c|c|c|c|c|c|c|c|c|c|c|}
\hline & \multicolumn{12}{|c|}{ Station No } \\
\hline Lag & 1 & 2 & 3 & 4 & 5 & 6 & 7 & 8 & 9 & 10 & 11 & 12 \\
\hline 1 & -.50727 & -.49839 & -.51344 & -.54797 & -.51726 & -.52228 & -.57953 & -.55488 & -.42870 & -.33529 & -.36948 & -.48254 \\
\hline 2 & 0.06676 & 0.01455 & 0.02005 & 0.08271 & 0.06822 & 0.03880 & 0.09453 & 0.06346 & -.06210 & -.18069 & 0.05137 & 0.05681 \\
\hline 3 & -.10495 & -.07746 & -.03376 & -.08238 & -.14187 & -.08302 & -.00489 & 0.00632 & -.12521 & -.05923 & 0.00799 & -.11842 \\
\hline 4 & 0.02718 & 0.02449 & -.01401 & 0.02524 & 0.10781 & 0.03974 & -.08603 & -.05501 & 0.05401 & 0.06498 & -.08638 & 0.01507 \\
\hline 5 & 0.18561 & 0.22253 & 0.19923 & 0.13041 & 0.08457 & 0.21110 & 0.22106 & 0.14546 & 0.27684 & 0.24975 & 0.10616 & 0.04987 \\
\hline 6 & -.24215 & -.24862 & -.22715 & -.09526 & -.10326 & -.26643 & -.22963 & -.14108 & -.29952 & -.22720 & -.19368 & 0.01772 \\
\hline 7 & 0.03461 & 0.03321 & 0.03026 & -.04413 & -.03345 & 0.06399 & 0.10467 & 0.01056 & 0.06867 & -.12054 & 0.08219 & -.11550 \\
\hline 8 & -.01393 & -.02430 & -.02059 & -.02102 & -.02140 & -.00952 & -.07902 & -.04267 & -.05037 & 0.10300 & -.03158 & -.01392 \\
\hline 9 & 0.07693 & 0.10023 & 0.17467 & 0.1814 & 0.18505 & 0.03456 & 0.19800 & 0.18207 & 0.05888 & 0.07506 & 0.08904 & 0.29851 \\
\hline 10 & -.04491 & -.07911 & -.18569 & -.23429 & -.24001 & -.00345 & -.21792 & -.19250 & 0.06998 & -.01565 & -.00076 & -.35263 \\
\hline 11 & 0.06995 & 0.06444 & 0.11300 & 0.23135 & 0.24472 & 0.00850 & 0.13946 & 0.15369 & -.05958 & -.01173 & -.03272 & 0.32198 \\
\hline 12 & -.01230 & 0.01228 & 0.01361 & -.17646 & -.16039 & .018980 & -.00528 & -.07056 & 0.13039 & 0.08090 & 0.05023 & -.30476 \\
\hline
\end{tabular}


In the next step of model determination, the stations with the same steady-state distribution are collected in the same station group and the transition frequencies observed for each station are combined to estimate the transition matrices of these station groups.

The 12 station groups respectively consist of 1st group 13 stations, 2nd group 12 stations, 3rd group 11 stations, 4th group 8 stations, 5th group 4 stations, 6th group 3 stations, 7th group 2 stations and the following groups, namely $8,9,10,11$ and 12 th groups only 1 station; this can be observed from Table 2 . The first three of these station groups consist of all of 7 different geographical regions of Turkey, the 4th station group consists of 4 different regions, the 5th and 6th station groups consist of 3 different regions and the 7th and later station groups consist of stations from only 1 geographical region. In the 1 st station group there are 4 stations from the Black Sea region and in the 2nd station group there are 3 stations from the Eastern Anatolia and Central Anatolia as in the highest frequencies. And in the 3rd station group there are 3 stations from the Black Sea region and in the 4th station group there are 4 stations from the Black Sea region as in the highest frequencies.
Since the magnitude and even the direction of change in many meteorological variables is uncertain, in this study it is developed and studied many numbers of models as possible with different approaches. Each of these models which use a quadratic programming technique can be generally expressed as follows (Floudas and Visweswaran, 1995):

$$
\operatorname{Max} f(\underline{x})=c^{T} \underline{x}-\frac{1}{2} \underline{x}^{T} Q \underline{x}
$$

subject to (ST)

$$
A \underline{x} \leq \underline{b}, \quad \underline{x} \geq \underline{0},
$$

where $\underline{x}^{T}$ is the transpose of vector $\underline{x}$, and the order relations in vectors and matrices are componentwise. As seen, a quadratic programming problem consists of a quadratic objective function and linear constraints. In our approach, the right-hand side constants of linear constraints, that is, the upper bounds are important because of the size of average temperature variability and the uncertainty of its direction of change. The models given as a quadratic programming problem can be explicitly formulated as follows:

$$
\operatorname{Min} \sum_{i=1}^{12} x_{i}^{2} \text { or (sometimes } \operatorname{Max} \sum_{i=1}^{12} \sum_{j \neq i}^{12} x_{i} x_{j} \text { ) }
$$

ST

$$
\begin{aligned}
& \sum_{i=1}^{12} x_{i} P_{i} \leq(\geq) P_{j} ; j=1, \ldots, 12 \\
& \sum_{i=1}^{12} x_{i}=1 \\
& x_{i} \geq 0 ; i=1,2, \ldots, 12
\end{aligned}
$$

where the variable $X_{i}$ denotes the weight of $i_{\text {th station group and }} P_{i}$ denotes the Least Square Estimation of transition matrix of $i_{\text {th }}$ station group. As mentioned in the following, the different models have been achieved by increasing assumptions and consequently increasing the number of constraints. Among these models, according to the assumptions used, there are the models giving precedence and not-giving precedence to the number of stations in station groups, the model bounded 
by the transition matrix closest to all transition matrices and the model bounded by the symmetric transition matrix closest to all the transition matrices in the constraint, the models derived from the first two models by adding the constraints with the squares and fourth powers of transition matrices.

Table 4 shows the number of non-zero solutions that the station groups rank among and the order of sizes of these solutions in quadratic programming models. As an example, the station group 1 having 13 stations ranks among 45 non-zero solutions in which 36 of them are $\geq 0.05$ and 10 of them are in the first order. Similarly, the station group 12 having only one station ranks among 49 non-zero solutions in which 35 of them are $\geq 0.05$ and 21 of them are in the first order.

Table 4. Non-zero solution types related to station groups.

\begin{tabular}{|c|c|c|c|c|}
\hline $\begin{array}{c}\text { Station } \\
\text { Group No }\end{array}$ & $\begin{array}{c}\text { \# of } \\
\text { Stations }\end{array}$ & $\begin{array}{c}\text { \# of non-zero } \\
\text { solutions }\end{array}$ & $\begin{array}{c}\text { \# of solutions } \\
\geq 0.05\end{array}$ & $\begin{array}{c}\text { \# of solutions } \\
\text { in the first } \\
\text { order }\end{array}$ \\
\hline 1 & 13 & 45 & 36 & 10 \\
\hline 2 & 12 & 42 & 31 & 5 \\
\hline 3 & 11 & 47 & 36 & 5 \\
\hline 4 & 8 & 49 & 35 & 6 \\
\hline 5 & 4 & 47 & 38 & 8 \\
\hline 6 & 3 & 47 & 36 & 12 \\
\hline 7 & 2 & 42 & 35 & 6 \\
\hline 8 & 1 & 41 & 22 & 1 \\
\hline 9 & 1 & 43 & 30 & 15 \\
\hline 10 & 1 & 49 & 36 & 3 \\
\hline 11 & 1 & 39 & 30 & 21 \\
\hline 12 & 1 & 49 & 35 & \\
\hline
\end{tabular}

Table 5. Some values for the non-zero solution types given in Table 3 and their means.

\begin{tabular}{|c|c|c|c|c|c|c|}
\hline $\begin{array}{c}\text { Station } \\
\text { Group } \\
\text { No }\end{array}$ & \multicolumn{2}{|c|}{ Solutions $<0.05$} & \multicolumn{2}{|c|}{ Solutions $\geq 0.05$} & \multicolumn{2}{c|}{$\begin{array}{c}\text { Mean Weights } \\
\text { of }\end{array}$} \\
\hline & Min $^{*}$ & Max & Min & Max & $>0$ & $\geq 0.05$ \\
\hline 1 & 0.00094 & 0.04344 & 0.05347 & 0.82278 & 0.15125 & 0.18076 \\
\hline 2 & 0.00094 & 0.04689 & 0.05347 & 0.99998 & 0.09509 & 0.11742 \\
\hline 3 & 0.00001 & 0.04689 & 0.05205 & 0.60236 & 0.07823 & 0.09440 \\
\hline 4 & 0.00000 & 0.04689 & 0.05128 & 0.78002 & 0.10377 & 0.13309 \\
\hline 5 & 0.01410 & 0.04689 & 0.05205 & 0.99994 & 0.09865 & 0.14947 \\
\hline 6 & 0.00001 & 0.04689 & 0.05205 & 1.00000 & 0.16274 & 0.20596 \\
\hline 7 & 0.00008 & 0.04388 & 0.05205 & 0.99999 & 0.11039 & 0.12840 \\
\hline 8 & 0.00000 & 0.04852 & 0.05084 & 1.00000 & 0.12821 & 0.21986 \\
\hline 9 & 0.00094 & 0.04689 & 0.05346 & 0.75281 & 0.07996 & 0.10362 \\
\hline 10 & 0.00001 & 0.04689 & 0.05148 & 1.00000 & 0.12468 & 0.16192 \\
\hline 11 & 0.00001 & 0.04689 & 0.05151 & 0.69623 & 0.12098 & 0.14966 \\
\hline 12 & 0.00004 & 0.04863 & 0.05219 & 1.00000 & 0.25892 & 0.34932 \\
\hline
\end{tabular}

*The 0.00000 values on the table are actually non-zero values such that $<0.00001$.

Here, it is obvious that the comments to be made by considering the station numbers in the station groups will be very striking and show the significance of each station group, and hence the importance of stations in this group in the annual mean temperature changes. From Table 5, as an example, the station group 5 having 4 stations has the minimum value 0.0140 and the maximum value 0.04689 in the non-zero solutions $<0.05$, 
while it takes at least 0.05205 and at most 0.99994 values in the non-zero solutions $\geq 0.05$, and the corresponding means of these solutions are 0.09865 and 0.14947 respectively. Similarly, the station group 12 having only one station has the minimum value 0.00004 and the maximum value 0.04863 in the non-zero solutions $<0.05$, while it takes at least 0.05219 and at most 1.00000 values in the non-zero solutions $\geq 0.05$ and the corresponding means of these solutions are 0.25982 and 0.34932 , respectively.

Table 6. The MSE values and number of non-zero weights $<0.05$ and $\geq 0.05$ for the models of ranked and ordered data.

\begin{tabular}{|l|c|c|l|c|c|}
\hline Model $^{*}$ & $\begin{array}{c}\text { Ranked Data } \\
\text { MSE }\end{array}$ & $\begin{array}{c}\text { \# of } \\
\text { non-zero } \\
\text { weights }\end{array}$ & Model & $\begin{array}{c}\text { Ordered Data } \\
\text { MSE }\end{array}$ & $\begin{array}{c}\text { \# of non- } \\
\text { zero } \\
\text { weights }\end{array}$ \\
\hline MINSF3 - U & 0.511840 & $8(4)^{* *}$ & MINSR9 - U & 0.187396 & $3(2)$ \\
\hline MINCO12 - U & 0.512015 & $9(9)$ & GM - A & 0.187396 & $12(12)$ \\
\hline MINCO3 - U & 0.512454 & $9(6)$ & MAXCPSYM - A & 0.190957 & $7(5)$ \\
\hline MINCAB ${ }^{* * *}$ & 0.187396 & $12(12)$ & MINS5 - MINSF5 & 0.191590 & $4(1)$ \\
\hline & & & MIN5 - U & 0.191590 & $7(5)$ \\
\hline & & & MINCO5 - A & 0.191590 & $7(7)$ \\
\hline & & & MIN8 - A & 0.194454 & 1 \\
\hline & & & MINS8 - AU & 0.194454 & 1 \\
\hline
\end{tabular}

* Here A and U point out auto scaled and unscaled techniques for QSB program, respectively.

**The frequencies in the parentheses belong to the solutions $\geq 0.05$.

***Here, in essence GM - A and MINCAB models give the same solution in quadratic programming problem.

Table 7. The MADE values and number of non-zero weights $<0.05$ and $\geq 0.05$ for the models of ranked and ordered data.

\begin{tabular}{|l|c|c|l|c|c|}
\hline Model & $\begin{array}{c}\text { Ranked } \\
\text { Data } \\
\text { MSE }\end{array}$ & $\begin{array}{c}\text { \# of non- } \\
\text { zero } \\
\text { weights }\end{array}$ & Model & $\begin{array}{c}\text { Ordered } \\
\text { Data } \\
\text { MSE }\end{array}$ & $\begin{array}{c}\text { \# of } \\
\text { non-zero } \\
\text { weights }\end{array}$ \\
\hline MINSF4 - U & 2.475107 & $4(2)$ & MINSR9 - U & 1.002128 & $3(2)$ \\
\hline MINCO12 - U & 2.480284 & $9(9)$ & GM - A & 1.002128 & $12(12)$ \\
\hline MINSF3 - U & 2.480780 & $8(4)$ & MINCO12 - U & 1.019858 & $9(9)$ \\
\hline MINCAB & 1.002128 & $12(12)$ & MAXCPSYM - A & 1.020284 & $7(5)$ \\
\hline & & & MIN8 - A & 1.075461 & 1 \\
\hline & & & MINS8 - AU & 1.075461 & 1 \\
\hline
\end{tabular}


These models are given in detail as follows:

MINSF3:

$\operatorname{Min} \sum_{i=1}^{12} x_{i}^{2}$

ST
MINCO12:

$\operatorname{Min} \sum_{i=1}^{12} x_{i}^{2}$

ST
MINCO3:

MINSR9:

$\operatorname{Min} \sum_{i=1}^{12} x_{i}^{2}$

$\operatorname{Min} \sum_{i=1}^{12} x_{i}^{2}$

ST

ST $\begin{array}{llll}\sum_{i=1}^{12} x_{i} P_{i}^{2} \leq P_{3}^{2} & \sum_{i=1}^{12} x_{i} P_{i} \leq P_{12} & \sum_{i=1}^{12} x_{i} P_{i} \leq P_{3} & \sum_{i=1}^{12} x_{i} P_{i} \geq P_{9} \\ \sum_{i=1}^{12} x_{i} P_{i}^{4} \leq P_{3}^{4} & x_{i} \geq x_{i+1} ; i=1, \ldots, 8 & x_{i} \geq x_{i+1} ; i=1, \ldots, 8 & \sum_{i=1}^{12} x_{i} P_{i}^{2} \geq P_{9}^{2} \\ \sum_{i=1}^{12} x_{i}=1 . & x_{7} \geq x_{j} ; j=10,11,12 & x_{7} \geq x_{j} ; j=10,11,12 & \sum_{i=1}^{12} x_{i}=1 .\end{array}$

GM:

$\operatorname{Min} \sum_{i=1}^{12} x_{i}^{2}$

MAXCPSYM:

MINS5:

$\operatorname{Max} \sum_{i=1}^{12} \sum_{j \neq i}^{12} x_{i} x_{j}$

$\operatorname{Min} \sum_{i=1}^{12} x_{i}^{2}$

$\operatorname{Min} \sum_{i=1}^{12} x_{i}^{2}$

ST

ST

ST

ST

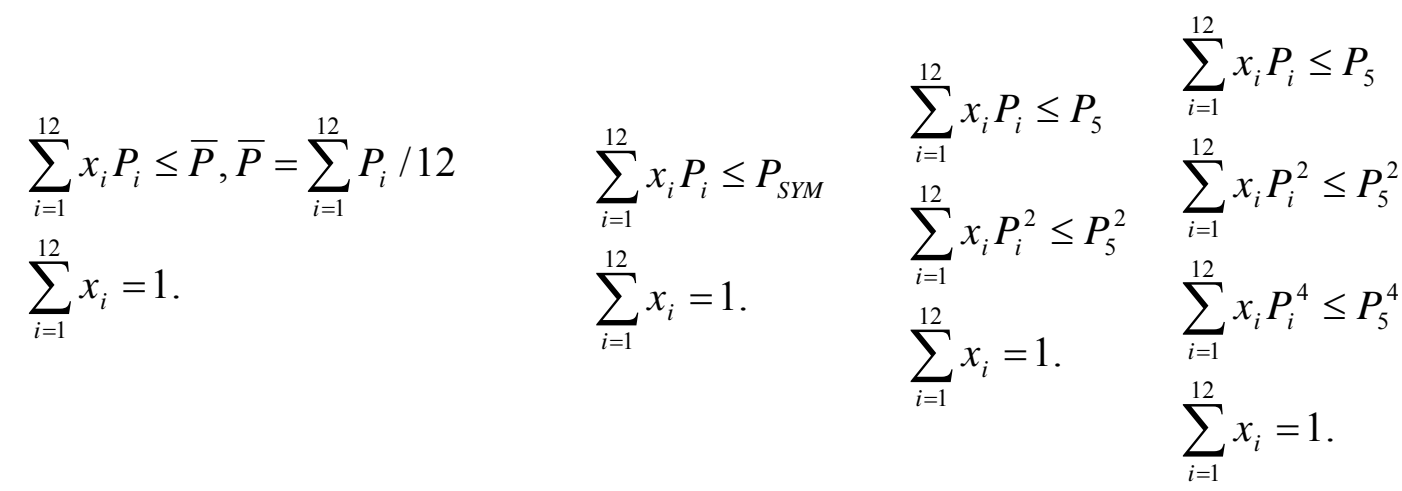
MIN5:

MINCO5:

MINSF4:

MINCAB:

$\operatorname{Min} \sum_{i=1}^{12} x_{i}^{2} \quad \operatorname{Min} \sum_{i=1}^{12} x_{i}^{2}$

$\operatorname{Min} \sum_{i=1}^{12} x_{i}^{2}$

$\operatorname{Min} \sum_{i=1}^{12} x_{i}^{2}$ 


$$
\begin{array}{llll}
\sum_{i=1}^{12} x_{i} P_{i} \leq P_{5} & \sum_{i=1}^{12} x_{i} P_{i} \leq P_{12} & \sum_{i=1}^{12} x_{i} P_{i}^{2} \leq P_{4}^{2} & \\
\sum_{i=1}^{12} x_{i}=1 . & x_{i} \geq x_{i+1} ; i=1, \ldots, 7 & \sum_{i=1}^{12} x_{i} P_{i}^{4} \leq P_{4}^{4} & \sum_{i=1}^{12} x_{i} P_{i} \leq P_{A B} \\
& \sum_{i=1}^{12} x_{i}=1 . & \sum_{i=1}^{12} x_{i}=1 . &
\end{array}
$$

MIN8:

MINS8:

$$
\operatorname{Min} \sum_{i=1}^{12} x_{i}^{2}
$$

ST

$$
\begin{aligned}
& \sum_{i=1}^{12} x_{i} P_{i} \leq P_{8} \\
& \sum_{i=1}^{12} x_{i}=1 .
\end{aligned}
$$

$\operatorname{Min} \sum_{i=1}^{12} x_{i}^{2}$<smiles>[SiH3]</smiles>

$\sum_{i=1}^{12} x_{i} P_{i}^{2} \leq P_{8}^{2}$

$\sum_{i=1}^{12} x_{i}=1$

where the matrix $P_{S Y M}$ in the model MAXCPSYM is a symmetric transition matrix which is the closest to all the transition matrices of station groups. In other words, the matrix $P_{S Y M}$ can be easily obtained by the following model MINAB with $b=a$, i.e., as the matrix $P_{\text {AA }}$ :

MINAB:

$$
\operatorname{Min} \sum_{i=1}^{12}\left(P_{i}-P_{A B}\right)^{2}, P_{A B}=\left[\begin{array}{cc}
a & 1-a \\
1-b & b
\end{array}\right]
$$

ST

$$
a \leq 1, b \leq 1, a \geq 0, b \geq 0 \text {. }
$$

The models MINSF3, MINCO12 and MINCO3 can be interpreted as minimizing the square of weights over the squares and fourth powers of transition matrices as constraints with $P_{3}$ and $P_{12}$, and additionally giving the precedence to the number of stations in station groups in the last 
two models, i.e., in the models MINCO12 and MINCO3. In the solutions with extra powers of transition matrices, it has been observed some slight corrections relative to models without extra powers. In the model MINSF3, it is obvious that there is no precedence to the number of stations in station groups. Similarly, the other models can be interpreted. Here, it should not be forgotten that in the comments to be made for each model, it would be very useful to consider station numbers in station groups; because a station group in the solution including stations from different climatic zones will give it extra meaning and importance. It is also useful to give such a detail that the quadratic programming problem does not provide a feasible solution when the MINAB model has an extra constraint $a \leq b$ on $a$ and $b$ values.

In this case, the quadratic programming problem gives positive solutions which do not satisfy

$$
\sum_{i=1}^{12} x_{i}=1
$$

constraint. By dividing the coefficients from zero by the sum

$$
\sum_{i=1}^{12} x_{i}
$$

that is, with normalization relatively usable solutions can be obtained.

\section{Linear Regression Approaches}

In this section, it is investigated the variation of the annual mean temperatures in Turkey by the linear regression approach. For this reason, it should be based on the assumption that they have approximately normal distribution whereas the increases and decreases observed in annual mean temperatures have nonnormal distributions as shown in the graphs below.

As seen from Table 8, the adjusted determination coefficients, $R_{a d j \text { 's show that }}^{2}$ the regression models on the single station group means are also valid such that the single station group means explain at least 57.5, and at most 98.4, percent of the variation of annual mean temperatures. In fact, it is easy to see that there is a positive correlation between the number of stations in the station groups and the coefficients of determination for the regression models on single station group means, which is exactly 0.5740 .

Table 8. Regression estimates of annual mean temperature changes by the station group means.

\begin{tabular}{|c|c|c|c|}
\hline & $R_{\text {adj }}^{2}$ & $R_{\text {adj }}^{2}$ \\
\hline$\hat{Y}_{i}=\begin{array}{r}-0.107793+0.980618 G_{1, i} \\
(0.023025)(0.025788)\end{array}$ & 0.9698 & $\begin{array}{r}\hat{Y}_{i}=0.006012+0.885888 G_{2, i} \\
(0.019989)(0.020419)\end{array}$ & 0.9767 \\
\hline$\hat{Y}_{i}=\begin{array}{r}0.009964+0.947467 G_{3, i} \\
(0.016670)(0.018150)\end{array}$ & 0.9838 & $\begin{array}{r}\hat{Y}_{i}=0.009881+1.02966 G_{4, i} \\
(0.041947)(0.051967)\end{array}$ & 0.8972 \\
\hline$\hat{Y}_{i}=\begin{array}{r}0.007066+1.12893 G_{5, i} \\
(0.046589)(0.064085)\end{array}$ & 0.8737 & $\begin{array}{r}\hat{Y}_{i}=-0.000063+0.740424 G_{6, i} \\
(0.038675)(0.034147)\end{array}$ & 0.9126 \\
\hline$\hat{Y}_{i}=\begin{array}{r}0.019806+0.640916 G_{7, i} \\
(0.047825)(0.037545)\end{array}$ & 0.8662 & $\begin{array}{r}\hat{Y}_{i}=0.022189+0.730136 G_{8, i} \\
(0.036470)(0.031614)\end{array}$ & 0.9205 \\
\hline$\hat{Y}_{i}=\begin{array}{r}0.022590+0.638294 G_{9, i} \\
(0.071469)(0.062106)\end{array}$ & 0.7012 & $\begin{array}{r}\hat{Y}_{i}=0.045251+0.853630 G_{10, i} \\
(0.066783)(0.075607)\end{array}$ & 0.7391 \\
\hline$\hat{Y}_{i}=\begin{array}{r}0.036170+0.889269 G_{11, i} \\
(0.085237)(0.113990)\end{array}$ & 0.5749 & $\begin{array}{r}\hat{Y}_{i}=0.001616+1.08271 G_{12, i} \\
(0.0726998)(0.107815)\end{array}$ & 0.6915 \\
\hline
\end{tabular}


Table 9. Goodness of fit summary for the fitted distributions.

\begin{tabular}{|l|c|c|c|c|c|c|}
\hline \multirow{2}{*}{ Distribution } & \multicolumn{2}{|c|}{$\begin{array}{c}\text { Kolmogorov } \\
\text { Smirnov }\end{array}$} & \multicolumn{2}{c|}{$\begin{array}{c}\text { Anderson } \\
\text { Darling }\end{array}$} & \multicolumn{2}{c|}{ Chi-Squared } \\
\cline { 2 - 7 } & Statistic & Rank & Statistic & Rank & Statistic & Rank \\
\hline Burr (4P) & 0.03231 & 2 & 1.9646 & 3 & 71.011 & 4 \\
\hline Dagum (4P) & 0.03108 & 1 & 1.9441 & 2 & 99.126 & 5 \\
\hline Gen. Logistic & 0.03281 & 3 & 1.8495 & 1 & 55.527 & 3 \\
\hline Normal & 0.06518 & 15 & 12.081 & 15 & 202.71 & 18 \\
\hline
\end{tabular}

Furthermore, assuming the correctness of the results obtained in quadratic programmingbased models, multiple linear regression models parallel to these results are also considered and the determination coefficients of these models are also found to be larger. The histograms of the increases and decreases of annual mean temperatures obtained from all stations and the distributions compiled are given in Figures 1 - 3, and the goodness of fit summary of these three distributions and the normal distribution by Easyfit program is given in Table 8 above.

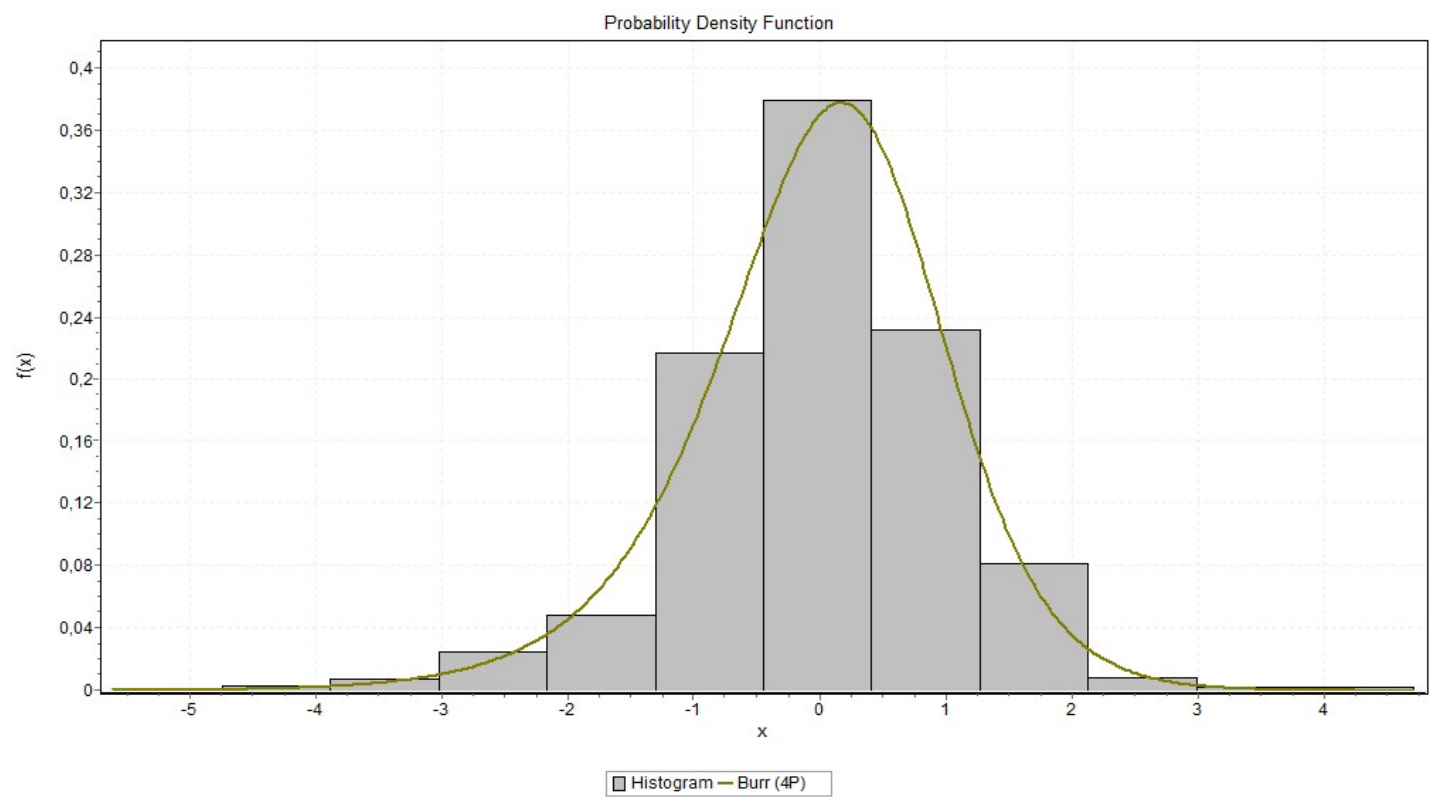

Fig 1. Four-parameter Burr distribution for annual mean temperature changes.

$(k=1.7487=\alpha, 98199.0=\beta, 64411.0-=\gamma, 64410.0)$ 


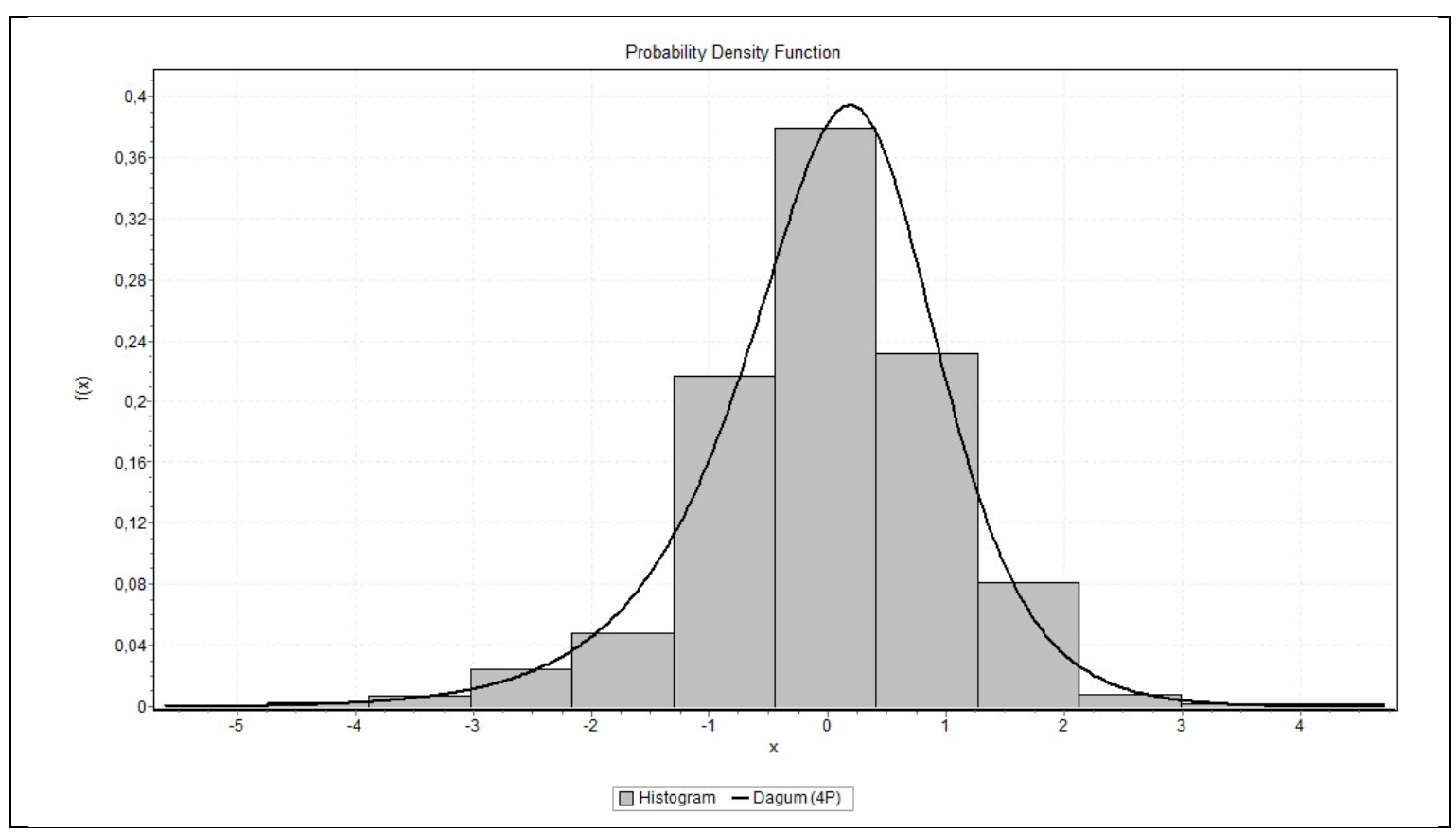

Fig 2. Four-parameter Dagum distribution for annual mean temperature changes. $(k=0.57823=\alpha, 90.427=\beta, 40.648-=\gamma, 40.204)$

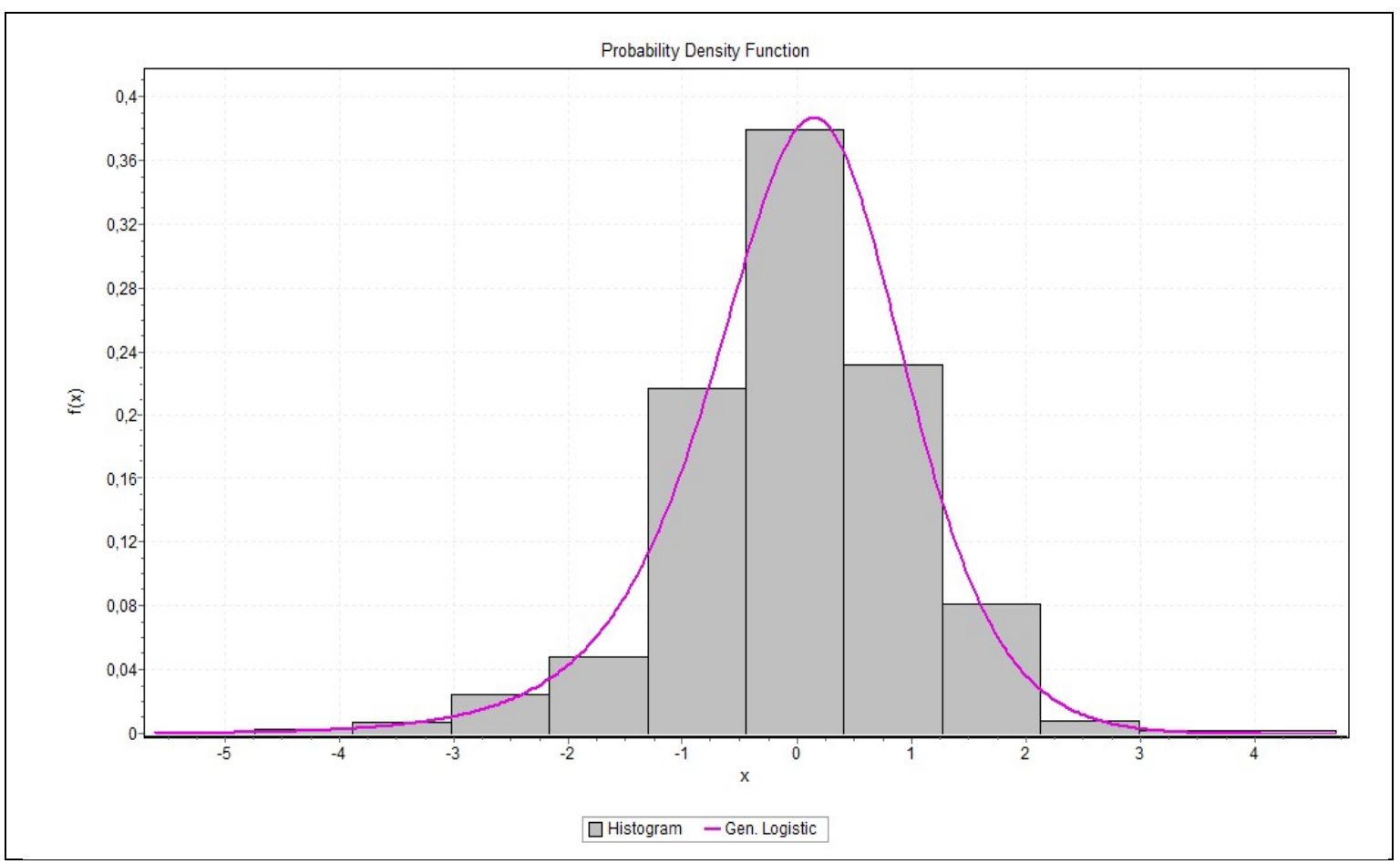

Fig 3. Three-parameter generalized logistic distributionfor annual mean temperature changes. $(k=0.07453=\sigma, 0.55838=\mu, 0.05912)$ 


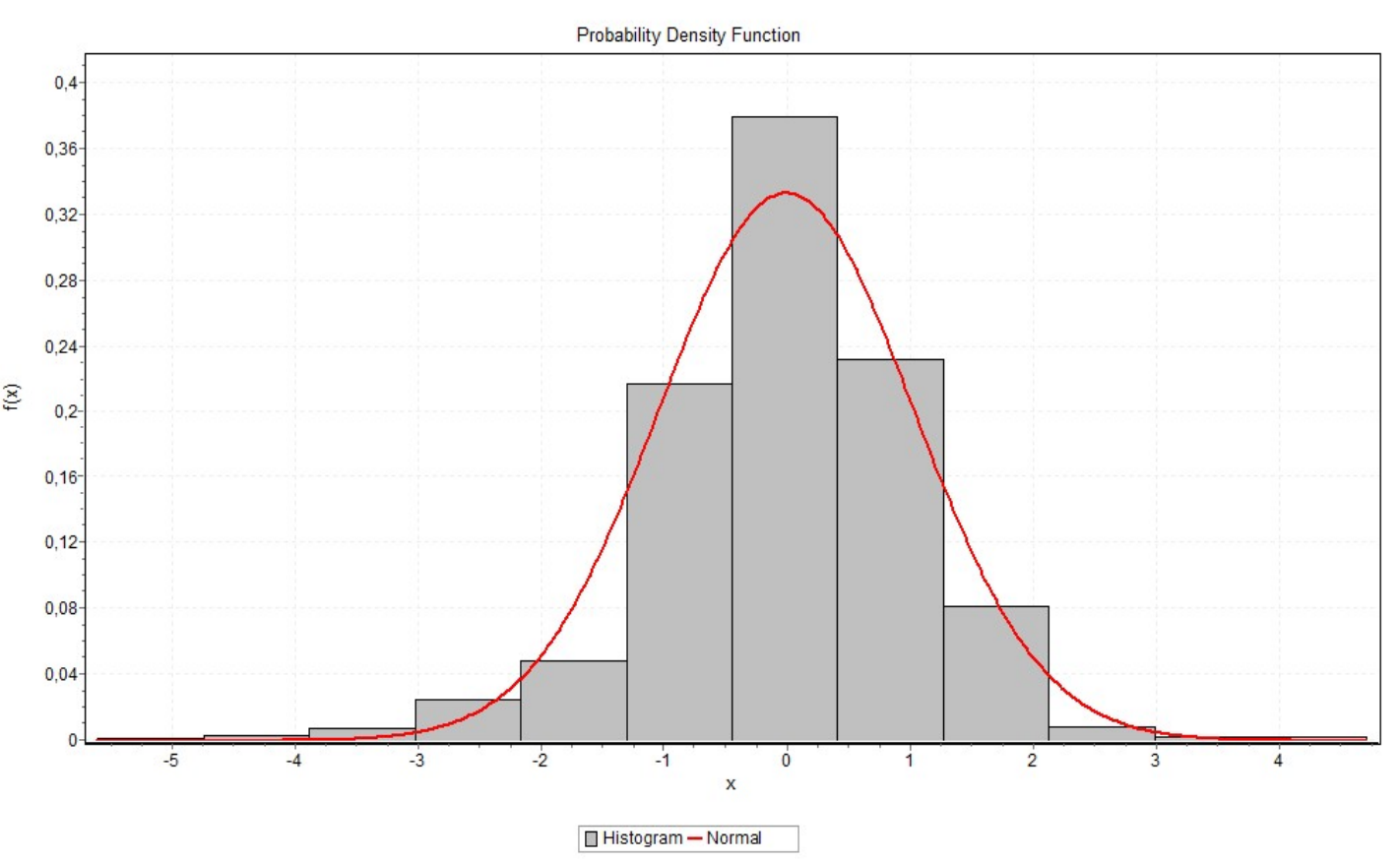

Fig 4. Normal distribution for annual mean temperature changes.

$(\sigma=1.0295, \mu=-0.00977)$

In multiple linear regressions, it should be noted that $C$ represents the constant, i.e. the intercept of the model. From the respect of coefficients in the models, a pleasing point here is that the 12th station is usually placed in the last orders in the case of multiple regressions whereas it is usually located in the first orders with its weights in quadratic programming solutions. Here it should not be forgotten that the station (group) 12, i.e., Izmir has a tendency to have the highest average annual temperatures among all of the station groups.

Table 10-1. Multiple linear regression estimates of annual mean temperatures changes of Turkey by the station group means.

\begin{tabular}{|c|c|c|c|c|c|}
\hline Model & & & $\begin{array}{c}\text { MLR } \\
\text { Estimate }\end{array}$ & $\begin{array}{c}\text { Induced }^{*} \\
\text { MLR Estimate }\end{array}$ & $R_{a d j}^{2}$ \\
\hline \multirow{10}{*}{ MINSF3-U } & & Weight & Coefficient & Coefficient & \multirow{10}{*}{$\begin{array}{c}.9956 \\
(.9952)\end{array}$} \\
\hline & $C$ & - & -.02327 & & \\
\hline & $G_{1}$ & .04994 & .25723 & .17175 & \\
\hline & $G_{2}$ & .03929 & .17865 & .26452 & \\
\hline & $G_{3}$ & .08062 & .30371 & .39672 & \\
\hline & $G_{4}$ & .09671 & .12212 & .13950 & \\
\hline & $G_{6}$ & .02910 & .02683 & & \\
\hline & $G_{7}$ & .02028 & .02543 & & \\
\hline & $G_{9}$ & .06663 & .01742 & & \\
\hline & $G_{12}$ & .61743 & .05146 & & \\
\hline
\end{tabular}

*Induced estimates consist of models which are regressed over statistically non-zero coefficients. 
Table 10-2. Multiple linear regression estimates of annual mean temperatures changes of Turkey by the station group means.

\begin{tabular}{|c|c|c|c|c|c|}
\hline Model & & & $\begin{array}{c}\text { MLR } \\
\text { Estimate }\end{array}$ & $\begin{array}{c}\text { Induced }^{*} \\
\text { MLR Estimate }\end{array}$ & $R_{a d j}^{2}$ \\
\hline \multirow{9}{*}{$\begin{array}{l}\text { MAXCPS } \\
\text { YM- A }\end{array}$} & & Weight & Coefficient & Coefficient & \multirow{9}{*}{$\begin{array}{c}.9885 \\
(.9880)\end{array}$} \\
\hline & $C$ & - & .01374 & & \\
\hline & $G_{3}$ & .07409 & .58463 & .71678 & \\
\hline & $G_{4}$ & .18581 & .21492 & .28625 & \\
\hline & $G_{5}$ & .22226 & .13929 & & \\
\hline & $G_{8}$ & .08445 & .07038 & & \\
\hline & $G_{9}$ & .00409 & .01378 & & \\
\hline & $G_{10}$ & .03015 & .10044 & .10021 & \\
\hline & $G_{12}$ & .39915 & -.16099 & -.14238 & \\
\hline \multirow{3}{*}{$\begin{array}{l}\text { MIN8 - A } \\
\text { MINS8 - } \\
\text { AU }\end{array}$} & & Weight & Coefficient & Coefficient & \multirow{3}{*}{$\begin{array}{c}.9205 \\
(.9217)\end{array}$} \\
\hline & $C$ & - & .02219 & & \\
\hline & $G_{8}$ & 1.00000 & .73014 & .73046 & \\
\hline \multirow{8}{*}{$\begin{array}{c}\text { MINCO12- } \\
\text { U }\end{array}$} & & Weight & Coefficient & Coefficient & \multirow{8}{*}{$\begin{array}{c}.9956 \\
(.9952)\end{array}$} \\
\hline & $C$ & - & -.02197 & & \\
\hline & $G_{1}$ & .08409 & .24704 & .17175 & \\
\hline & $G_{2}$ & .08409 & .25385 & .26452 & \\
\hline & $G_{3}$ & .08409 & .35053 & .39672 & \\
\hline & $G_{4}$ & .08409 & .10424 & .13950 & \\
\hline & $G_{5}$ & .08409 & -.03176 & & \\
\hline & $G_{12}$ & .57956 & .06538 & & \\
\hline \multirow{5}{*}{$\begin{array}{l}\text { MINSR9 - } \\
\text { U }\end{array}$} & & Weight & Coefficient & Coefficient & \multirow{5}{*}{$\begin{array}{c}.9712 \\
(.9719)\end{array}$} \\
\hline & $C$ & - & -.00105 & & \\
\hline & $G_{6}$ & .19958 & .46026 & .46022 & \\
\hline & $G_{9}$ & .75281 & .16611 & .16615 & \\
\hline & $G_{12}$ & .04761 & .34966 & .34960 & \\
\hline
\end{tabular}

*Induced estimates consist of models which are regressed over statistically non-zero coefficients. 
Table 10-3. Multiple linear regression estimates of annual mean temperatures changes of Turkey by the station group means.

\begin{tabular}{|c|c|c|c|c|c|}
\hline Model & & & $\begin{array}{c}\text { MLR } \\
\text { Estimate } \\
\end{array}$ & $\begin{array}{c}\text { Induced }^{*} \\
\text { MLR Estimate }\end{array}$ & $R_{a d j}^{2}$ \\
\hline \multirow{11}{*}{$\begin{array}{l}\text { MINCO3 - } \\
\text { U }\end{array}$} & & Weight & Coefficient & Coefficient & \multirow{11}{*}{$\begin{array}{c}.9956 \\
(.9955)\end{array}$} \\
\hline & $C$ & - & -.02648 & -.02012 & \\
\hline & $G_{1}$ & .08403 & .28841 & .23596 & \\
\hline & $G_{2}$ & .08403 & .25214 & .21767 & \\
\hline & $G_{3}$ & .08403 & .33962 & .38868 & \\
\hline & $G_{4}$ & .08403 & .15487 & .13655 & \\
\hline & $G_{5}$ & .08403 & -.07554 & & \\
\hline & $G_{6}$ & .00008 & -.01343 & & \\
\hline & $G_{7}$ & .00008 & .03930 & & \\
\hline & $G_{8}$ & .00008 & -.05797 & & \\
\hline & $G_{12}$ & .57962 & .06780 & & \\
\hline \multirow{14}{*}{$\begin{array}{l}\text { MINCAB } \\
\text { GM - A }\end{array}$} & & Weight & Coefficient & Coefficient & \multirow{14}{*}{$\begin{array}{c}.9966 \\
(.9966)\end{array}$} \\
\hline & $C$ & & -.014920 & & \\
\hline & $G_{1}$ & .08333 & .20243 & .14224 & \\
\hline & $G_{2}$ & .08333 & .23024 & .28641 & \\
\hline & $G_{3}$ & .08333 & .25262 & .33662 & \\
\hline & $G_{4}$ & .08333 & .19702 & .16907 & \\
\hline & $G_{5}$ & .08333 & -.03581 & & \\
\hline & $G_{6}$ & .08333 & .02529 & & \\
\hline & $G_{7}$ & .08333 & .03598 & & \\
\hline & $G_{8}$ & .08333 & -.01808 & & \\
\hline & $G_{9}$ & .08333 & .00283 & & \\
\hline & $G_{10}$ & .08333 & .02615 & & \\
\hline & $G_{11}$ & .08333 & .05117 & .06693 & \\
\hline & $G_{12}$ & .08333 & .03347 & & \\
\hline
\end{tabular}

*Induced estimates consist of models which are regressed over statistically non-zero coefficients. 
Possible Approaches over Observed $a$ and $b$ Values

In this section, taking into consideration the 120 possible values of transition probabilities $0 \rightarrow 0, a$ and $1 \rightarrow 1, b$ in the estimates of transition matrices of station groups other than those mentioned in previous sections we give some summary results. In addition, we give the models with the right hand side constraint restriction by $P_{3}$, and by the transition probability matrix of the mean of annual mean temperature changes of all stations. The reason why we place the model with $P_{3}$ here is that the determination coefficient of the 3rd station group is larger than that of all other individual station groups. For the models based on the probabilities $a$ and $b$, it is worth noting that some of these models have not feasible solutions because of the constraints of quadratic programming problem (see Fig. 4 ). Fig. 4 also shows the transitions between the solutions on the boundaries. For example, on the first 'row' of Figure 4, the notation $G 12 \leftarrow G 10$ corresponds to the transition from Solution S1 to Solution S9, where the solutions evolve from G10 to G12, although G5 is also a part of the solution sometime. It should be noted here that the indices of station groups are in the magnitude order of weights in the solutions. Here any model with no feasible solution indicates that the tendency of increase/decrease in mean temperatures will not be in the direction of this model. On the other hand, Solution S92 specifically corresponds to the MIN8-A solution, and Solution S8 roughly coincides with the GMTPM solution:

$$
\operatorname{Min} \sum_{i=1}^{12} x_{i}^{2}
$$

ST

$$
\sum_{i=1}^{12} x_{i} P_{i} \leq P_{G M},, \sum_{i=1}^{12} x_{i}=1
$$

where $P_{G M}$ is the transition matrix estimated from the mean of annual mean temperature changes of all meteorological stations.

When the solutions are examined under similar thoughts, it is observed that the orders of magnitudes of the weights of station groups

change as the $a$ values decrease from big to small values. The weights of station groups can be summarized as follows: the upper left corner is G12 corner, the upper right corner is G10 corner, the lower left corner is G8 corner and the lower right corner is G6 corner (we mean S72 solution). In a sense, similar words can be said for the edges of the feasible region: the station $\mathrm{G} 12$ on the upper corner of left vertical edge having the greatest weight leaves its place to the station G8 on the lower side, while the solutions are accompanied by the station groups G4 and G5 in the middle orders and the station group G5 is left later. Again in the magnitude order, on the last line of Figure 4 (the row above the solution to S92), the solution containing the station groups G6, G11, G8 and G7 transforms into a solution consisting of the station groups G8, G12 and G4 on the left corner. In the solutions on the right side of the feasible region and even to the right of the column starting with S1 (except $\mathrm{S} 1$ ), and including S40 and S41, the station groups G10, G7, G6 and G1 take place and in the solution S50 the order changes as G7, G6 and G10, and in the solutions S51 and S52 the order changes as G6, G7 and G11. In the continuation of these rows towards the low, the solution S61 includes the station groups G6, G7, G10 and G11, and the solutions S62 and S63 include G6, G7 and G11 and G6, G11 and G7 as the first three components, respectively. On the bottom row, the solutions S73, S74 and S75 contain the station groups G6, G7 and G11.

Finally, consider the solutions S35, S36, S45 and S46 at the intersection with the largest number of station groups. Using the short notations given on the sides of Figure 4, these solutions are respectively $G 12,5,4,10,3,9,8,1,2,7,11,6$;

$G 12,8,4,5,3,9,1,2,10,11$;

$G 12,4,5,3,9,1,2,11,10,7,6$

and

$G 8,12,4,5,3,9,1,2,11,10$ 
Note that the solution groups S36 and S46 comprise 10 of station groups, while the solutions S35 and S45 include all station groups.

\section{Conclusion and Some Remarks}

In this study, using the observed average annual temperature values for 48 years in 58 meteorological stations of Turkey we examined some scenarios which could react on the future annual mean temperature changes. For this purpose, firstly, aggregating the Markov chains related to the annual mean temperatures of 58 stations by their steadystate distributions, 12 station groups are obtained and different quadratic programming models are considered. In these models, the right side transition matrices in the constraints indicate the direction of the temperature changes in a sense and the weights are the projections on 12 station groups which show the importance of each station group.

Similar to the application in annual mean temperatures, for the differences in mean rainfall between successive years, if we take 0 for the negative or zero cases, and 1 for the positive cases, it is also obvious that the same approach can be applied to the changes in mean precipitation. Even the Markov chain approach given here can be used to examine for the increases and decreases in mean temperatures and mean precipitations together, with a state space

$$
S=\{(i, j): i, j=0,1\} \text {. }
$$

However, in such a case it may be necessary to take into account the dependence structure between mean temperatures and mean precipitations.

Some of the findings of this study are: the station groups of 4, 10 and 12 have the largest number of non-zero solutions. The station groups of 3, 5 and 6 are in second order in respect of number of non-zero solutions. The third, fourth and fifth orders pertain to the station groups 1, 9 and the station groups 2 and 7 , respectively. Here, it should be noted that station groups do not take place lonely in the solutions. In these non-zero solutions, the station groups $12,10,6,1$, and 5 are the most frequently seen as the first order weights (see Table 4). In all non-zero solutions, in respect of the mean weights, the first five orders pertain to the station groups $12,6,1,8$ and 10 . In the solutions $\geq 0.05$ the orders of mean weights pertain to the station groups $12,8,6,1$ and 10 (see Table 5).

In the quadratic programming models, a variety of solutions have been obtained, ranging from solutions containing only 1 station group to solutions containing 12 station groups with different approaches. Some of these solutions are given in Section 2. In Section 3, regression models which try to regulate the annual mean temperatures of Turkey over the station groups with non-zero weights in the quadratic programming given in Section 2 are considered. Statistically, only the coefficients of these first four station groups were significant in the regression models against the quadratic programming solutions containing the first four station groups and/or some other station groups. The adjusted determination coefficient of these regression models is as high as 0.9956 . It should be noted that the first four station groups contain a total of 44 stations ( $75.9 \%$ of all stations).

And finally, in Section 4, some possible approaches over observed $a$ and $b$ values which are also related to the quadratic programming models are given in detail.

In the study, the predictions of mean temperature changes for the future are not included. That is the reason why these estimates increase the volume of the article and our changeability on how to use the weights obtained by quadratic programming. When the weights are taken as probabilistic or deterministic, it is possible to carry out different simulation studies. It may even be interesting to compare over aftcasts which one of the probabilistic or deterministic approaches is closer to reality. 


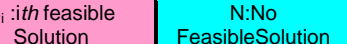

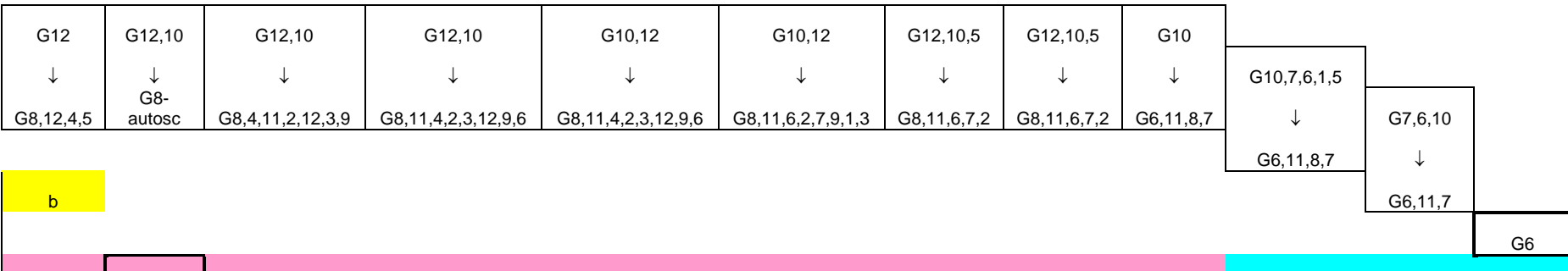

\begin{tabular}{|c|c|c|c|c|c|c|c|c|c|c|c|c|c|}
\hline 0,38095 & s9 & S8 & S7 & s6 & S5 & s4 & s3 & S2 & s1 & $\mathrm{N}$ & $\mathrm{N}$ & $\mathrm{N}$ & $\mathrm{G} 12 \leftarrow \mathrm{G} 10$ \\
\hline 0,33696 & s19 & s18 & S17 & S16 & S15 & S14 & $\mathrm{s} 13$ & $\mathrm{~s} 12$ & S11 & $\mathrm{s} 10$ & $\mathrm{~N}$ & $\mathrm{~N}$ & $\mathrm{G} 12,8 \leftarrow \mathrm{G} 10,7,6,1,5$ \\
\hline 0,26705 & $\mathrm{~s} 29$ & s28 & S27 & S26 & $\mathrm{S} 25$ & S24 & S23 & S22 & S21 & s20 & $\mathrm{N}$ & $\mathrm{N}$ & $\mathrm{G} 12,8 \leftarrow \mathrm{G} 10,7,6,1,9,2,5,3,11$ \\
\hline 0,25541 & s39 & S38 & s37 & S36 & S35 & S34 & S33 & S32 & s31 & s30 & $\mathrm{N}$ & $\mathrm{N}$ & $\mathrm{G} 12,8,4,5 \leftarrow \mathrm{G} 10,7,6,1,9,2,5,11,3$ \\
\hline 0,23810 & S49 & S48 & S47 & S46 & S45 & S44 & s43 & S42 & S41 & s40 & $\mathrm{N}$ & $\mathrm{N}$ & $\mathrm{G} 12,8,4,5 \leftarrow \mathrm{G} 10,7,6,1,2,11,9,3,5$ \\
\hline 0,19444 & $\mathrm{~s} 60$ & S59 & S58 & S57 & s56 & S55 & S54 & S53 & S52 & S51 & $\mathrm{s} 50$ & $\mathrm{~N}$ & $\mathrm{G} 8,12,4,5 \leftarrow \mathrm{G} 7,6,10$ \\
\hline 0,18421 & S71 & s70 & s69 & s68 & $\mathrm{S} 67$ & s66 & $\mathrm{s} 65$ & s64 & $\mathrm{s} 63$ & $\mathrm{~s} 62$ & $\mathrm{~s} 61$ & $\mathrm{~N}$ & $\mathrm{G} 8,12,4,5 \leftarrow \mathrm{G} 6,7,10,11$ \\
\hline 0,13725 & N & s82 & s81 & s80 & s79 & S78 & S77 & s76 & S75 & S74 & S73 & s72 & $\mathrm{G} 8,12,4 \leftarrow \mathrm{G} 6$ \\
\hline 0,11765 & N & s91 & s9o & s89 & S88 & S87 & s86 & S85 & s84 & s83 & N & $\mathrm{N}$ & $\mathrm{G} 8,12,4 \leftarrow \mathrm{G} 6,11,8,7$ \\
\hline 0,05263 & $\mathrm{~N}$ & s92 & $\mathrm{N}$ & $\mathrm{N}$ & $\mathrm{N}$ & $\mathrm{N}$ & N & $\mathrm{N}$ & $\mathrm{N}$ & $\mathrm{N}$ & $\mathrm{N}$ & N & G8-autosc \\
\hline
\end{tabular}

Fig 5. Solutions on the feasible region for the models with the observed $a$ and $b$ values. 


\section{References}

Anisimov, V.V. (2008), Switching Processes in Queueing Models, John Wiley, Hoboken, NJ.

Ball, J.E., Luk, K.C.(1998), Modeling spatial variability of rainfall over a catchment, J. Hydrol. Eng., 3, 122-130. https://doi.org/10.1061/(ASCE)108 4-0699(1998)3:2(122)

Boucherie, R.J. and van Dijk, N.M. (Eds.), Markov Decision Processes in Practice, International Series in Operations Research \& Management Science, Springer, 2017.

Can, A., Atimtay, A.T.(2002), Time series analysis of mean temperature data in Turkey, Applied Time Series, 4, 20-23.

Cao, X.R., Ren, Z.Y., Bhatnagar, S., Fu, M., and Marcus, S. (2002), A time aggregation approach to Markov decision processes, Automata, 38: 929-943.

Clark, E.B.(2008), A framework for modelling stochastic optimisation algorithms with Markov chains, PhD Thesis, University of York, Department of Electronics, November, 2008.

Dessler, A.E., Introduction to Modern Climate Change, Cambridge University Press, 2012.

Dobrovolski, S.G. (2000), Stochastic Climate Theory: Models and Applications, Berlin, Springer.

Dogan, M., Ulke, A., Cigizoglu, H.K.(2015), Trend direction changes of Turkish temperature series in the first half of 1990s, Theor. Appl. Climatol., 121:23-29.

Floudas, C.A., Visweswaran, V. (1995), Quadratic optimization, In: Horst R., Pardalos P.M., Handbook of Global Optimization, Vol 2. Springer, Kluwer, Dordrecht, pp 217-269.

Imkeller, P. and von Storch, J.-S. (Eds.), Stochastic Climate Models. Progress in Probability, Springer, Basel, Birkhäuser Verlag, 2001.

Kadioglu, M.(1997), Trends in surface air temperature data over Turkey, Int. J. Climatol., 17, 511-520.

Karaburun, A., Demirci, A., Kara, F.(2012), Analysis of spatially distributed annual, seasonal and monthly temperatures in Marmara region from 1975 to 2006,
Ozean Journal of Applied Sciences, 5(2), 131-149.

Stein, M.L.(1999), Interpolation of Spatial Data: Some Theory for Kriging, Springer.

Tayanc, M., Dalfes, H.N., Karaca, M., Yenigun, O.(1998), A comparative assessment of different methods for detecting inhomogeneities in Turkish temperature data set, Int. J. Climatol., 18, 561-578.

Turkish General Directorate of Meteorology Weather Station (2012) Databanks of Turkish General Directorate of Meteorology, Ankara

Ustaoglu, B.(2012), Trend analysis of annual mean temperature data using MannKendall rank correlation test in CatalcaKocaeli peninsula, northwest of Turkey for the period of 1970-2011, IBAC, 2, 276-287.

http://dspace.epoka.edu.al/handle/1 /379

von Storch, H. and Navarra, A. (Eds.), Analysis of Climate Variability: Applications of Statistical Techniques, Berlin, Springer Verlag, 1995.

Yin, G.G. and Zhang, Q. (2013), ContinuousTime Markov Chains and Applications: A- Two- Time Scale Approach, Second Edition, Springer. 